\title{
A PALAVRA-GESTO NA NARRATIVA DE EÇA DE QUEIRÓS
}

\section{Vitor Hugo Fernandes Martins}

O grande e belo corpo de Maria, embrulhado mum roupão branco de seda, movia-se, espreguiçava-se languidamente sobre o leito branco.

Eça de Queirós

(Os Maias)

\section{RESUMO}

Neste ensaio sobre a narrativa de José Maria Eça de Queirós (1845 - 1900), mais especificamente sobre três romances, a saber, $O$ Mistério da Estrada de Sintra (1870), Os Maias (1888) e A Tragédia da Rua das Flores (1980), intentamos mostrar e demonstrar um procedimento estilístico, no qual o signo gestual vale tanto quanto o verbal.

A partir de amostragens textuais dos supraditos romances, propomo-nos a decodificar a significação do corpo e da voz na apresentação e na composição das personagens queirosianas.

\section{Introdução}

A obra de Eça de Queirós, razoavelmente extensa, composta de romances, novelas, contos, crônicas, estudos, epistolário, crítica, polêmica, literatura de viagens, hagiografia, alcançou um nível universal. E universal, precisamente porque antes de tudo ela reflete, em essência, o nacional, o regional, o particular. Conforme a máxima, Eça cantou a sua aldeia (Póvoa do Varzim): imortalizou-se. Do mesmo modo que o fizeram

Especialista em Literatura Brasileira pela Universidade de Brasilia (UnB). Professor da Universidade Católica de Goiás (UCG). 
outros dois Monumentos da Literatura Portuguesa, Luís de Camões e Fernando Pessoa.

Por outro lado, o modo eciano de escrever, o como cantar a sua aldeia, os seus tiques e bossas, enfim, o seu estilo, fizeram do romancista português um paradigma. Conhecendo a fundo a mecânica da Lingua Portuguesa, Eça de Queirós soube como transgredi-la, subvertê-la. Ao fazê-lo, revitalizou-a. Guardadas as devidas proporções, Guimarães Rosa viria a fazer o mesmo, já nos Novecentos, deste lado do Atlântico. Na verdade, muitas afinidades eletivas entre o lusiada e o tupiniquim, como, por exemplo, a procura obcecada pela palavra expressiva, a "paixão da forma", para lembrarmo-nos de uma das mais envolventes personagens do autor de Os Maias. ${ }^{1}$

Dentre os tiques (marcas recorrentes) e as bossas (marcas inovadoras) que constituem o estilo eciano, os seus estilemas, que foram tão amorosa e laboriosamente estudados por Ernesto Guerra da Cal, ${ }^{2}$ um há que nos chama a atenção, exatamente por sua recorrência, por sua novidade, quanto à apresentação e à composição de suas personagens. Referimonos à técnica de que se vale Eça para, mais do que narrar, mostrar o que vai fora e dentro de suas criaturas ficcionais. É sabido, ainda por quem tenha pouca familiaridade com a obra eciana, que suas personagens se caracterizam muito pelo fisico, atraem-nos principalmente pela aparência, pelo retrato exterior que o romancista insiste, compraz-se - parece-nos em realçar. Aliás, como é praxe acontecer no romance naturalista, onde o corpo vale mais do que a alma, a Fisiologia mais do que a Psicologia, os instintos mais do que os remorsos. Basta lembrarmo-nos das personagens que povoam $O$ Cortiço (1890), de Aluísio Azevedo, sem dúvida, a obra naturalista mais bem-acabada, mais bem-sucedida da Literatura Brasileira, para descobrirmos, no corpo da linguagem, a linguagem do corpo.

É certo, as personagens de Eça tendem a ser planas. Tipificam-se, não raro. Razão pela qual Machado de $\mathrm{Assis}^{3}$ critica a ausência de vida interior de Luísa, personagem de O Primo Basilio (1878). Para o "bruxo do Cosme Velho", a heroina eciana tem alma inerte, é tão-somente um titere. Todavia, não nos parece que assim seja. A leitura de Machado sobre Eça não é leviana, não tem vícios, não é feita a partir do ódio, da camaradagem ou da indiferença, as três chagas da critica, segundo o criador de Capitu. Trata-se de uma crítica ciente e consciente, de muita 
acuidade, de muita sinceridade. No entanto, não há como concordar com Machado em algumas de suas considerações. Parece escapar-lhe o sentido intimo (a nosso ver, nem tão intimo assim) da criação da personagem Luísa. Ora, esta, sem dúvida, sofre de bovarysmo. Motivo por que tem de ser mostrada como uma mulher vazia, fútil, cúpida. Do ócio ao cio, um nada. Se investigarmos a galeria das heroinas (e também de alguns heróis, sublinhemos) ecianas, encontraremos um número admirável de Bovarys. Os três romances que nos propusemos a ler para este ensaio apresentamnos - para abonar o que acabamos de dizer - três personagens que padecem do mal de Bovary. A ver. A primeira, a Condessa:

Pois bem! que faço

Aborreço-me.

Logo que ele sai, bocejo, abro um romance, ralho com criadas, penteio os filhos, tono a bocejar, abro a janela, olho.

Passa um rapaz, airoso ou forte, louro ou trigueiro, imbecil ou mediocre. Olhamo-nos. Traz um cravo ao peito, uma gravata complicada. Tem o cabelo mais bonito do que o do meu marido, o talhe das suas calças é perfeito, usa botas inglesas, pateia as dançarinas!

Estou encantada! Sorrio-lhe. Recebo uma carta sem espírito e sem gramática. Enlouqueço, escondo-a, beijo-a, releio-a e desprezo a vida. $^{4}$

Depois, a mais Bovary de todas as heroinas de Eça, Maria Eduarda:

Para abrandar desde já o papá, Pedro quis dar ao pequeno o nome de Afonso. Mas nisso Maria não consentiu. Andava lendo uma novela de que era herói o último Stuart, o romanesco principe Carlos Eduardo; e, namorada dele, das suas aventuras e desgraças, queria dar esse nome a seu filho... Carlos Eduardo da Maia! Um tal nome parecialhe conter todo um destino de amores e façanhas. ${ }^{5}$

Por fim, outra das Bovarys de Eça, Genoveva:

(Victor) Encontrou Genoveva languidamente deitada no sofá da sala, com um livro na mão. Ergueu-se sobre o cotovelo, pediu-lhe desculpa de o receber assim, mas estava doente, desde a véspera e, deixando cair o livro no tapete, com um gesto desfalecido, indicou-lhe uma cadeira, ao pé, perguntando:

- Então, que há de novo? ${ }^{6}$ 
As passagens citadas, que envolvem personagens femininas importantes, talvez protagonistas, são bastante ilustrativas: mostram-nos como estão, por extensão, como são as personagens queirosianas. Melhor dito: o corpo delas tem voz. Dai por que o narrador esforce-se por privilegiar posturas físicas, que indiciam posturas animicas, e invariavelmente a partir de estranhamentos semânticos, sintáticos e morfológicos.

A Machado de Assis e a muita gente tão sensivel quanto ele, escaparam essas sutilezas psico-estilisticas de Eça de Queirós. O romancista português ainda hoje é tido, por alguns leitores desatentos ou de má vontade, como um escritor de pena bruta, crua, impassivel. Triste engano. Suas narrativas, se bem vistas, têm sugestão, tempero, paixão. É o que demonstraremos a seguir.

\section{A Palavra-gesto no Romance-epistolar}

O Mistério da Estrada de Sintra, narrativa policialesca, epistolar, escrita a quatro mãos (Eça de Queirós e Ramalho Ortigão, que já haviam feito, também de parceria, As Farpas (1871), crônicas sobre política, literatura e costumes), é o primeiro romance publicado de Eça. Já aí aparecem os tiques e as bossas que vão caracterizar o estilo eciano e vão rejuvenescer a prosa de ficção portuguesa. Já ai surgem o sensualismo, o erotismo, o sensacionismo, tão reprovados por Machado de Assis e tão aprovados pelos leitores de Eça de Queirós. Entretanto, trata-se de uma estratégia de composição que merece ser entendida para ser apreciada. Assim, as descrições e marcações fisicas, corporais e gestuais das personagens são indices de personalidade. A propósito desse tipo de signo, Peirce ensina-nos:

Psicologicamente, a ação dos indices depende de uma associação por contiguidade, e não de uma associação por semelhança ou de operações intelectuais. ${ }^{?}$

Vale dizer: os movimentos dos corpos, não raro lânguidos (com certeza, a palavra-chave no léxico de Eça), relacionam-se a intenções, a intensões, expressam-nas. Por isso Ernesto Guerra da Cal, com sua agudeza habitual, observa a respeito de Eça e do estilo eciano: 
Esta mórbida volúpia dos sentidos é uma das pedras angulares de sua vida espiritual, repassada, como o seu estilo, dum sensacionismo que se estende ao mundo interior. ${ }^{8}$

Desse modo, o sensorialismo eciano, que se manifesta através de um descritivismo expressivo, plástico, que nos faz visualizar o que se narra, revela também como é a personagem interiormente. Nesse sentido, merecem destaque igualmente os cenários, os figurinos, que necessariamente devem ser lidos, pois são caracteres das personagens. Leia-se, por exemplo, a funcionalidade do recorrente objeto livro (entenda-se felicité, passion, ivresse), nos três excertos acima, para uma melhor caracterização das personagens (só faltou dizer-se que o que elas liam era o romance Madame Bovary, de Gustavo Flaubert...).

Assim, num romance de plurifocalização narrativa, como é $O$ Mistério da Estrada de Sintra, Eça já experimenta a palavra-gesto. E é esse procedimento freqüente (naturalmente, junto a outros) que nos autoriza afirmar que $O$ Mistério, em seus nove blocos narrativos, é uma escritura eciana, com uma ou outra intervenção de Ramalho Ortigão, o que talvez se dê mais no conteúdo do que na forma. Vejamos o primeiro bloco narrativo, "Exposição do Dr.

Maquinalmente entrei na alcova, sentei-me na cama, encostei um braço no travesseiro.

Então, não sei como, olhei, reparei, vi, com estranha comoção, sobre a alvura do travesseiro, preso num botão de madrepérola, um longo cabelo louro, um cabelo de mulher.

Não me atrevi logo a tocar-lhe, pus-me a contemplá-lo, ávida e longamente.

“- Era certo então! Ai estás, pois! Encontro-te finalmente!... Pobre cabelo! Apieda-me a simplicidade inocente com que te ficaste ai, patente, descuidado, preguiçoso, lânguido! Podes ter maldade, podes ter malvadez, mas não tens malícia, não tens astúcia. Tenho-te nas mãos, fito-te com os meus olhos; não foges, não estremeces, não coras; dás-te, consentes-te, facilitas-te, meiga, doce, confiadamente... E, no entanto, tênue, exigua, quase microscópica, és uma parte da mulher que eu adivinhava, que eu antevia, que eu procuro! É ela autora do crime? É inteiramente inocente? É apenas cúmplice? Não sei, nem tu mo poderás dizer." 
O narrador-personagem, reparemos, narra-mostrando. Os verbos, preferencialmente, de ação, de movimento, sofrem um estranhamento em virtude da relação desviante estabelecida com os advérbios e os adjetivos. A ação, o objetivo, assim, sugerem-nos o agente, o subjetivo. Os substantivos, por sua vez, quase sempre concretos, passam também por uma modificação inesperada, a partir da sinédoque (és uma parte da mulher que eu adivinhava, que eu antevia, que eu procuro) e da hipálage (cabelo preguiçoso, lânguido) - figuras caríssimas a Eça de Queirós - e com as quais o narrador enriquece o perfil da personagem. Não nos esqueçamos de que a caricatura é outro traço peculiar do estilo queirosiano.

O excerto a seguir, ainda de O Mistério da Estrada de Sintra, e igualmente longo, parece-nos imprescindivel aqui como averbação à nossa leitura, até porque se constrói por outro viés, por outra focalização, e o objeto do foco não é mais uma personagem feminina. Trata-se do bloco "A Confissão Dela". Vejamo-lo:

Mas ao pé de mim, sentado num sofá com um abandono asiático, estava un homem verdadeiramente original e superior, um nome conhecido - Carlos Fradique Mendes. Passava por ser apenas um excêntrico, mas era realmente um grande espirito. Eu estimava-o, pelo seu carácter impecável, e pela feição violenta, quase cruel, do seu talento. Fora amigo de Carlos Baudelaire e tinha como ele o olhar frio, felino, magnético, inquisitorial. Como Baudelaire, usava a cara toda rapada: e sua maneira de vestir, de uma frescura e de uma graça singular, era como a do poeta seu amigo, quase uma obra de arte, ao mesmo tempo exótica e correcta. Havia em todo o seu exterior o que quer que fosse da feição romântica que tem o Satã de Ary Scheffer, e ao mesmo tempo a fria exactidão de um gentleman. Tocava admiravelmente violoncelo, era um terrivel jogador de armas, tinha viajado no Oriente, estivera em Meca, e contava que fora corsário grego. O seu espirito tinha um imprevisto profundo e que fazia cismar: fora ele que dissera da pálida duquesa de Morny: elle a la bêtise meloncolique d'un ange. O imperador citava muitas vezes este dito, como sendo conjuntamente a critica profunda de uma fisionomia e de um carácter. ${ }^{10}$

A narradora, a Condessa W, na abertura do excerto, através da palavra-gesto, mostra-nos a cena, traça-nos o retrato-escrito de Fradique Mendes. ${ }^{11}$ Observemos a indicação espacial e corporal da personagem. Sobretudo as posturas, a física e a anímica, que nos vêm da locução adverbial com um abandono asiático. Pronto. Está apresentada e, cinesi- 
camente, indicialmente, metonimicamente, caracterizada a personagem. Nós, leitores, de imediato visualizamos ai uma fisionomia (um dândi) e um carácter (um cabotino com todos os effes e erres, o qual, aliás, tem muita parecença com outros notáveis dândis e cabotinos ecianos, como, por exemplo, João da Ega, de Os Maias).

\section{A Palavra-gesto no Romance-mural}

Os Maias, a obra-prima eciana, segundo consenso da critica, são um romance mural. Vale dizer: pela história do clã dos Maias, lê-se a história lisboeta, portuguesa, européia, oitocentista.

Com Os Maias, efetivamente, Eça chega, aos quarenta e três anos, à maturidade como romancista. Depuram-se-lhe o Logos, o Pathos, o Ethos. Mais do que nunca, agora sabe o como, o quê e o porquê narrarmostrar. Carlos Reis, professor da Faculdade de Letras de Coimbra, especialista em Eça de Queirós, comentando-lhe a produção literária, diz que há um Eça romântico, um Eça naturalista c

há, finalmente, um Eça eclético, isto é, aberto a várias estéticas e sobretudo não enquadrado de modo rigoroso em qualquer corrente literária especifica. $^{12}$

De fato, mas o que aproxima o Eça fantasista (mas sempre sobre o real) de $O$ Mandarim (1880) do Eça picaresco de $A$ Reliquia (1887), do Eça muralista de Os Maias, do Eça desgraçadamente romântico de $A$ Cidade e as Serras (1901)? Nada, se considerarmos os temas; tudo, se considerarmos o estilo. Buffon é inevitável neste passo: o estilo é o homem. Quer dizer, todos esses Eças, a despeito do variado assunto de que tratem, têm uma só maneira de narrar-mostrar, na qual a palavra-gesto é estilema que se evidencia fartamente. Sirva-nos de exemplo a passagem abaixo, de Os Maias:

Mas un dia, em Roma, Maria sentiu o apetite de Paris. Parecialhe fatigante o viajar, assim, aos baloiços das caleças, só para ir ver lazzaroni engolir fios de macarrão. Quanto melhor seria habitar um ninho acolchoado nos Campos Elisios, e gozarem ali um lindo Inverno de amor! Paris estava seguro, agora, com o principe Luis Napoleão... 
Além disso, aquela velha Itália clássica enfastiava-a já: tantos mármores eternos, tantas Madonas começavam (como ela dizia pendurada languidamente do pescoço de Pedro) a dar tonturas à sua pobre cabeça! Suspirava por uma boa loja de modas, sob as chamas do gás, ao rumor do Boulevard... Depois tinha medo da Itália, onde todo o mundo conspirava. $^{13}$

Nesse excerto, em que Eça exercita admiravelmente o discurso indireto e o indireto livre, fica à vista o que vimos chamando de palavragesto no estilo queirosiano. Assim, a volubilidade (enfastiava- $a$ ), a voluptuosidade (apetite, ninho acolchoado, gozarem ali um lindo Inverno de amor!, pendurada languidamente ) e a futilidade (Suspirava por uma boa loja de modas, sob as chamas de gás, ao rumor do Boulevard...) de Maria Eduarda são narradas-mostradas, via um léxico, a um tempo, preciso e polissêmico e que nos remete não só ao corpo mas também à mente das personagens. Ou, na feliz expressão do já citado ensaista gale$\mathrm{go}^{14}$, através das percepções duais.

Ainda no que toca ao excerto, tenhamos olhos para a solução a que o narrador recorre, a qual vem corroborar o nosso estudo acerca da palavra-gesto na narrativa eciana. Quase ao final do parágrafo, a voz narrativa, em $3^{\text {a }}$. pessoa, mais mostra do que narra. Haja vista os parênteses. Ou seja, como se fosse uma rubrica, uma marcação, melhor, uma indicação teatral; corporal, gestual, portanto. Assim: o patente pressupondo o (latente).

Em outra passagem de Os Maias, vemos:

Nesse momento a porta envidraçada abriu-se de golpe. Ega exclamou: "Saúde ao poeta!"

E apareceu um individuo muito alto, todo abotoado numa sobrecasaca preta, com uma face escaveirada, olhos encovados, e sob o nariz aquilino, longos, espessos, românticos bigodes grisalhos: já todo calvo na frente, os anéis fofos de uma grenha muito seca caiam-lhe inspiradamente sobre a gola: e em toda a sua pessoa havia alguma coisa de antiquado, de artificial e de lúgubre.

Estendeu silenciosamente dois dedos ao Dâmaso, e abrindo os braços lentos para Craft, disse numa voz arrastada, cavernosa, ateatrada:

- Então és tu, meu Craft! Quando chegaste tu, rapaz? Dá-me cá esses ossos honrados, honrado inglês! ${ }^{15}$ 
É-nos apresentada agora outra personagem importante do romance, o poeta Tomás de Alencar. O narrador, ao retratá-lo exteriormente, retrata-o também internamente. Caricaturiza-o. Trata-se de um decadente, por fora e por dentro. Dessa maneira, o vestuário (todo abotoado numa sobrecasaca preta), as feições (face escaveirada, olhos encovados, os anéis fofos de uma grenha muito seca caiam-lhe inspiradamente sobre a gola, alguma coisa de antiquado, de artificial, de ligubre), os gestos (estendeu silenciosamente dois dedos, e abrindo os braços lentos para Craft), as falas (voz arrastada, cavernosa, ateatrada) - e não só os longos, espessos, bigodes grisalhos - são românticos. Todas essas palavras-gestos (ênfase nossa), evidentemente, pertencem ao léxico do Romantismo. Eça de Queirós, mais uma vez, logra fazer-nos ver o que se narra: traduz, pelos exteriores, os interiores de suas personagens. Dessa maneira, parece-nos melhor falarmos de um enunciador mostrador do que de um narrador ou mesmo descritor.

\section{A Palavra-gesto no Romance-tragédia}

A Tragédia da Rua das Flores, um dos romances póstumos de Eça de Queirós, concebido, conforme A.Campos Matos, ${ }^{16}$ entre 1877-1878, em Newcastle, Inglaterra, e publicado somente em 1980, simultaneamente em Portugal e no Brasil, tematiza um tabu, que os naturalistas logo se apressaram em TOTEMizar: o incesto. Eça já o havia tematizado em $O s$ Maias. Aí, temos a história do incesto fraternal. Inicialmente, tratado de maneira romântica, uma vez que os dois amantes, Carlos Eduardo e Maria Eduardo (da Maia), não se sabem irmãos; atribui-se, assim, ao fatalismo o incesto. Porém, páginas adiante, o narrador mostra-nos Carlos conscientemente incestuoso. Quer dizer, o incesto agora explica-se pelo determinismo. Maria Eduarda, por seu turno, será sempre inconscientemente incestuosa, quando das relações sexuais.

Já o incesto em A Tragédia da Rua das Flores é o edipiano. Victor da Silva e Genoveva, filho e mãe, afastados um do outro, tendo esta abandonado aquele ainda menino, depois de adultos se encontram em Lisboa e se sentem atraidos um pelo outro. Novamente, Eça faz concessões ao Romantismo: o incesto, então, se explicará pelo fatum, pelo inelutável. 
Portanto, Victor e Genoveva não agem, não determinam suas relações incestuosas; ao contrário, são determinadas por elas. Uma das bulas do Naturalismo prescreve:

É necessário esclarecer: não somos fatalistas, somos deterministas, o que não é de forma alguma a mesma coisa. ${ }^{17}$

Victor, um dos protagonistas, nos é narrado-mostrado assim:

Como a cidade, em redor, lhe parecia mesquinha, e todos aqueles homens nas casas escuras, adormecidas, nos braços de mulheres triviais, dignos de compaixão e subalternos.

Jurou tornar-se digno dela: ter toilettes elegantes; ler todos os romances, todos os dramas, para se penetrar do espirito, da graça mordaz e rica, saber manejá-la como um florete. Escreveria versos, pediria dinheiro ao tio Timóteo. E quando entrou no seu quarto, foi-se contemplar no espelho, calmo e formoso; arranjou os cabelos. Em que teria ela reparado, na sua fisionomia? O que lhe agradava? Era o seu cabelo preto, anelado, os seus olhos rasgados e quebrados? O seu buço tão simpático, tão macio? A sua pele que tinha o leve tom de um pálido marmóreo?

Como vemos, a personagem também padece de bovarysmo, que não é uma doença exclusiva das mulheres, pois. Lemos Victor como bovarysta à medida que lemos, em seu monólogo, a sua fala gestual. Desse modo, toilettes elegantes estão para a futilidade, para a vacuidade; romances, dramas, versos, florete, para a fantasia, para o diletantismo, para o exotismo; foi-se contemplar no espelho, para a vaidade, para o narcisimo. Para Victor (Eça?), o que importa é a aparência, o corpo: Em que teria ela reparado na sua fisionomia? (ênfase nossa). A ênfase que a personagem dá à sua aparência revela-nos a sua essência, o seu pleno vazio.

Noutra passagem do romance, o narrador-mostrador põe em cena Genoveva:

Ela levou as mãos à cabeça, com um gesto medonho, os olhos sairam-lhe das órbitas, a boca aberta queria gritar, arrimou-se à borda da mesa, os seus braços retesaram-se; levou a mão convulsamente ao colar, a mola despedaçou-se: e dando passos vagos pela sala, com sons roucos e tremores, os braços ao alto, batendo o ar, foi cair sobre o tapete, com os braços abertos. ${ }^{19}$ 
Nada mais expressivamente cinésica do que essa passagem. À maneira de Jocasta, o corpo (cabeça, olhos, boca, braços, mãos) de Genoveva é que fala, que significa a sua dor, a sua tragédia. É a anagnórisis.

\section{Conclusões}

Os resultados a que chegamos, após a leitura de $O$ Mistério da Estrada de Sintra, Os Maias e A Tragédia da Estrada de Sintra, revelam-nos que, primeiro, o narrar-mostrar, ainda que possa ser detectado em outros autores, especialmente entre os realistas e naturalistas, como o nosso Manuel Antônio de Almeida, em suas deliciosas Memórias de um Sargento de Milicias (1852-1853, em folhetins; 1854-1855, em livro), em Eça de Queirós, é uma marca registrada, personalissima, psicoestilística, a qual está evidente em qualquer página que seja de Eça de Queirós, não importa a que gênero ela pertença.

Depois, outra revelação intrigante: ao narrar pela palavra, Eça exercita, em princípio, só o literário; mas, ao narrar-mostrar, também o gestual. E este, sem dúvida, nos impressiona mais do aquele. $\mathrm{O}$ romancista, dessa maneira, torna-se teatrólogo. Por isso, não gratuitamente a prosa de ficção eciana vem sendo com freqüência encenada, em Portugal e no Brasil. Prova disso foi a recente adaptação, em 1992, pela Rede Globo de Televisão, do romance $O$ Primo Basilio, para uma minissérie. O curioso disso tudo é Eça ter feito teatro somente no romance, na novela, no conto, na crônica, na lenda hagiográfica...

Por fim, mais uma revelação que merece destaque: Eça era um esteta da palavra, ou um logoteta, seus textos provam-no; era, também, obsessivamente cinésico, por isso não se limitava apenas a narrar, a descrever, desejava, tinha necessidade de mostrar (-se?). Sem dúvida que, no fundo, esse procedimento desvela compulsão, matéria do inconsciente das criaturas e do criador, e faz o corpo significar mais do que a voz. Enfim, a palavra-gesto. Ou um exercicio, levado a bom termo e avant la lettre, de tradução intersemiótica. 
RÉSUMÉ

Dans cet essai, nous nous proposons de montrer et de démontrer une stratégie narrative, un procédé stylistique propre et innovateur de Eça de Queirós en ce qui concerne la présentation et la composition des personnages, à partir de la lecture de trois oeuvres du romancier portugais.

\section{NOTAS}

1. Afonso da Maia. Personagem do romance Os Maias.

2. Lingua e Estilo de Eça de Queiroz. Quarta Edição. Coimbra, Livraria Almedina, 1981. Com certeza, a investigação mais acurada e percuciente feita até hoje sobre o estilo de Eça de Queirós. O ensaista galego debruça-se, com paciência e ciência, sobre a palavra e a frase ecianas, notando e anotando o que há nelas de desvio, de invenção, de poesia.

3. Machado de Assis, em "Eça de Queirós: O Primo Basilio", polêmica "apreciação crítica", que valeu ao seu autor algumas contrariedades e contendores, aponta os defeitos graves, gravissimos, do romance de Eça: fundamentalmente, a inexistência de uma verdade moral; o acentuado das cores e das linhas; o culto do escuso e do torpe; a representação minuciosa e servil do intimo e do infimo. De acordo com a crítica machadiana, Eça, "com o seu dom de observação, aliás pujante, é complacente em demasia; sobretudo é exterior e superficial". (p.913) (grifos nossos)

4. QUEIRÓS, Eça de \& ORTIGÃO, Ramalho. O Mistério da Estrada de Sintra, p.251.

5. QUEIRÓS, Eça de. Os Maias, p.38.

6. QUEIRÓS, Eça de. A Tragédia da Rua das Flores, p.111.

7. PEIRCE, Charles S. Semiótica, p. 76.

8. CAL, Ernesto Guerra da. Op. cit., p. 82.

9. QUEIRÓS, Eça de. O Mistério da Estrada de Sintra, p. 51.

10. Ibidem, p. 257-258.

11. Fradique Mendes, personagem heterônima, criação atribuida a Jaime Batalha dos Reis, Antero de Quental e Eça de Queirós. Poeta satânico, à Baudelaire, filósofo, dândi, diletante e sensual. Alguns ecianos 
vêem em Fradique o alter-ego de Eça, que desenvolve, episodicamente, a personagem em $\mathrm{O}$ Mistério e transcreve-lhe o epistolário em Correspondência de Fradique Mendes (1888). De fato, Fradique, além de lembrar Eça, lembra também, e muito, João da Ega (Os Maias).

12. REIS, Carlos. Introdução à Leitura d'Os Maias, p. 14.

13. QUEIRÓS, Eça de. Os Maias, p. 32.

14. CAL, Ernesto Guerra da. Op. cit., p. 183.

15. QUEIRÓS, Eça de. Os Maias, p. 159.

16. MATOS, A Campos. Dicionário de Eça de Queirós.

17. ZOLA, Émile. O Romance Experimental, p. 52.

18. QUEIRÓS. A Tragédia da Rua das Flores, p. 109.

19. QUEIRÓS. Ibidem, p. 347.

\section{REFERÊNCIAS BIBLIOGRÁFICAS}

BRANDÃO, Junito de Souza. Mitologia Grega. Petrópolis: Vozes, 19861987. $3 \mathrm{v}$.

CAL, Ernesto Guerra da. Lingua e Estilo de Eça de Queiroz. 4. Ed. Versão portuguesa definitiva de Elsie Allen da Cal. Coimbra: Livraria Almedina, 1981.

CARREIRO, José Bruno. Os Maias - adaptação teatral do original de Eça de Queirós. Lisboa: Imprensa Nacional, Casa da Moeda, 1984.

HALLIDAY, Tereza Lúcia. O Que é Retórica. São Paulo: Brasiliense, 1990. (Coleção Primeiros Passos, 232).

MACHADO DE ASSIS, Joaquim Maria. "Eça de Queirós: O Primo Basilio". In: Machado de Assis - Obra Completa. Rio de Janeiro: Nova Aguilar, 1986, v. 3.

MATOS, A Campos (Org. e Coord.). Dicionário de Eça de Queirós. Lisboa: Editorial Caminho, 1988.

MOISÉS, Massaud. A Criação Literária (Prosa).13. Ed. São Paulo: Cultrix, 1987.

OLIVEIRA, Ana Cláudia. Fala Gestual. São Paulo: Perspectiva, 1992. (Coleção Estudos, 128) 
OLIVEIRA, Solange Ribeiro de. Literatura e Artes Plásticas. Ouro Preto: Editora da Universidade Federal de Ouro Preto, 1993.

PIERCE, Charles Sanders. Semiótica. São Paulo: Perspectiva, 1977. Tradução de José Teixeira Coelho Neto. (Coleção Estudos, 46)

PINTO, Júlio. 1,2,3 da Semiótica. Belo Horizonte: Editora da Universidade Federal de Minas Gerais, 1995.

PLAZA, Julio. Tradução Intersemiótica. São Paulo: Perspectiva, 1987. (Coleção Estudos, 93)

QUEIROZ, Eça de, ORTIGÃO, Ramalho. O Mistério da Estrada de Sintra. Lisboa: Livros do Brasil, s/d.

Os Maias. Porto: Porto Editora, 1989.

. A Tragédia da Rua das Flores. Lisboa: Livros do Brasil,s/d.

RECTOR, Mônica, TRINTA, Aluizio Ramos. Comunicação do Corpo. São Paulo: Ática, 1990. (Série Principios, 1985)

REIS, Carlos, LOPES, Ana Cristina M. Dicionário de Teoria da Narrativa. São Paulo: Ática, 1990. (Série Fundamentos, 29)

SANTAELlA, Lúcia. A Assinatura das Coisas. Rio de Janeiro: Imago, 1992.

SARAIVA, António José, LOPES, Óscar. História da Literatura Portuguesa. 16. Ed. Porto: Porto Editora, s/d.

YLLERA, Alicia. Estilistica, Poética y Semiótica Literária. 3. Ed. Madri: Alianza Editorial, 1986.

ZOLA, Émile. O Romance Experimental. São Paulo: Perspectiva, 1979. Tradução de Ítalo Caroni e Célia Barrettini 